\title{
Predicting phenological development in winter wheat
}

\author{
Qingwu Xue $^{1,3, *}$, Albert Weiss ${ }^{1}$, P. Stephen Baenziger ${ }^{2}$ \\ ${ }^{1}$ School of Natural Resource Sciences and ${ }^{2}$ Department of Agronomy and Horticulture, University of Nebraska-Lincoln, \\ Lincoln, Nebraska 68583-0728, USA \\ ${ }^{3}$ Present address: Northwestern Agricultural Research Center, Montana State University, 4570 Montana 35, \\ Kalispell, MT 59901
}

\begin{abstract}
Accurate prediction of phenological development is important in the winter wheat Triticum aestivum agroecosystem. From a practical perspective, applications of pesticides and fertilizers are carried out at specific phenological stages. In crop-simulation modeling, the prediction of yield components (kernel number and kernel weight) and wheat-grain yield relies on accurate prediction of phenology. In this study, a nonlinear multiplicative model by Wang \& Engel (WE) for predicting phenological development in differing winter wheat cultivars was evaluated using data from a 3 yr field experiment. In the vegetative phase (emergence to anthesis) the daily development rate $(r)$ was simulated based on the product of a maximum development rate $\left(R_{\max }\right)$ in the vegetative phase, a temperature response function $[f(T)]$, a photoperiod response function $[f(P)]$, and a vernalization response function $[f(V)] . f(T)$ was a nonlinear function of the 3 cardinal temperatures for phenological development (minimum, $T_{\min }$, optimum, $T_{\mathrm{opt}}$, and maximum, $\left.T_{\max }\right) . f(P)$ was an exponential function of the actual and critical photoperiods and a sensitivity parameter unique to each cultivar. $f(V)$ was calculated using $f(T)$ based on the cardinal temperatures for vernalization $\left(T_{\min , \mathrm{vn}}, T_{\mathrm{opt}, \mathrm{vn}}\right.$, and $\left.T_{\text {max,vn }}\right)$. In the reproductive phase, $r$ was simulated based on the product of $R_{\max }$ for the reproductive phase and $f(T)$. Predictions from this nonlinear model were compared to predictions from the phenology submodel of CERES-Wheat V3.0 (CW3). The nonlinear model performed very well for predicting phenological development in the 3 winter wheat cultivars, the mean root mean square error (RMSE) ranged from 2.9 to $4.1 \mathrm{~d}$ from booting to maturity. For the CW3 model, the mean RMSE ranged from 4.8 to $5.9 \mathrm{~d}$ for the same phenological stages. The WE model predicted double ridge with a mean RMSE of $7.3 \mathrm{~d}$. Both models predicted terminal spikelet with a mean RMSE ranging from 6.2 to $7.1 \mathrm{~d}$. The WE model was generally a better predictor of phenology between booting and maturity than the CW3 model.
\end{abstract}

KEY WORDS: Phenology · Temperature · Photoperiod · Vernalization · Modeling · Triticum aestivum L.

\section{INTRODUCTION}

The life cycle of winter wheat Triticum aestivum L. includes a series of phenological stages; each stage represents an important change in morphology and function of the different plant organs. Accurate prediction of these stages has practical as well as researchoriented applications. From a practical perspective, applications of pesticides and fertilizers are carried out at specific phenological stages. Cultivars adapted to specific environments are dependent upon phenological development. In crop-simulation modeling, the prediction of yield components (kernel number and kernel weight) and grain yield also depend upon the accurate prediction of phenology (Shaykewich 1995, Cao \& Moss 1997, Kirby \& Weightman 1997). Crop- 
simulation models have also been used to assess the effects of climate change on wheat responses (Tubiello et al. 1995, 1999, Mearns et al. 1999, Ghaffari et al. 2001). The major phenological stages in wheat are emergence (EM), double ridge (DR), terminal spikelet (TS), jointing (JT), booting (BT), heading (HD), anthesis (AN), and maturity (MA).

Phenological models can be divided into 3 categories. The first category is an additive method. For example, Perry et al. (1987) and Summerfield et al. (1991) simulated the daily development rate, $r\left(\mathrm{~d}^{-1}\right)$, using a temperature response function, $f(T)$, and a photoperiod response function, $f(P)$, assuming no interaction between photoperiod and temperature. The second category is a multiplicative method. This type of model assumes an interaction and simulates $r$ from sowing or emergence (EM) by multiplying $f(T)$ by $f(P)$ (Robertson 1968, Angus et al. 1981, Weir et al. $1984)$ and by a vernalization response function, $f(V)$ (Wang \& Engel 1998). When this accumulated rate reaches a predefined value, a specified phenological stage has been reached, e.g. 1 for anthesis (AN) and 2 for maturity (MA), assuming emergence begins at 0 (Angus et al. 1981, Wang \& Engel 1998). The third category is the most-limiting-factor method. In CERES-Wheat (Ritchie 1991), it is assumed that both photoperiod and vernalization affect phenological development between EM and terminal spikelet (TS). However, only the most-limiting factor is considered, i.e. the minimum value of the photoperiod or vernalization response functions, in determining the daily development rate. The multiplicative model may better represent the relationship between phenological development and environmental variables because studies have indicated that there are interactions between temperature, photoperiod, and vernalization effects (Slafer \& Rawson 1994, Cao \& Moss 1997). However, which concept (additive, multiplicative, or limiting factor) best represents the natural process greatly depends on how the concept was incorporated into the model. The multiplicative method has the advantage of adhering to the concept that natural systems respond to the interactions of many stimuli and factors.

The determination of the temperature $[f(T)]$, photoperiod $[f(P)]$, and vernalization $[f(V)]$ response functions is very important in predicting the rate of phenological development $\left(\mathrm{d}^{-1}\right)$ regardless of the type of phenological model used. Linear temperature functions, using the thermal-time $\left(\mathrm{TT}^{\circ}{ }^{\circ} \mathrm{C} \mathrm{d}\right)$ concept, have been used to predict phenological development in many models (e.g. Weir et al. 1984, Ritchie 1991, McMaster et al. 1992). However, other researchers have found that a non-linear temperature response function is a better measure of phenology (Angus et al.
1981, Rawson 1993, Shaykewich 1995). Some forms of the Beta function have been successfully used to quantify this temperature response (Yin et al. 1997, Wang \& Engel 1998, Yan \& Hunt 1999a).

The response of the rate of phenological development to photoperiod has been found to be nonlinear and several different functions, including quadratic (Ritchie 1991, Cao \& Moss 1997), exponential or power (Angus et al. 1981, Saarikko \& Carter 1996, Wang \& Engel 1998), and Beta function (Yin et al. 1997), have been used to describe $f(P)$. The exponential response of the rate of phenological development to photoperiod has been used to predict phenology in wheat and other crops such as rice Oryza sativa L. and soybean Glycine $\max ($ L.) Merr. (Sinclair et al. 1991, Horie 1994).

Of the 3 response functions, probably least is known about vernalization. As noted above, CERES-Wheat uses a most-limiting-factor approach to deal with vernalization in the period from EM to TS. In contrast Weir et al. (1984) modified the accumulation of TT in the period from EM to DR by the interaction of photoperiod and vernalization response functions. Cao \& Moss (1997) used a similar approach as Weir et al. (1984), but include devernalization within the first $30 \%$ of the vernalization day requirement and a decreasing influence of photoperiod on plant development after TS. Yan \& Hunt (1999b) used a form of the Beta function to represent the vernalization response function. The advantage of this approach is that a continuous curve is used rather than 3 linear segments, as in Weir et al. (1984) and Ritchie (1991), thus taking into account nonlinear responses near the minimum, optimum, and maximum temperatures. Regardless of how the vernalization response is calculated and the number of days to achieve vernalization, the algorithm should take into account plant age at the onset of the vernalization process and its influence on final leaf number (Wang et al. 1995a,b, Brooking 1996).

The objective of this study was to evaluate a nonlinear, multiplicative phenology model composed of temperature and vernalization functions based on Wang \& Engel (1998) and a photoperiod function based on Angus et al. (1981) to determine major phenological stages of winter wheat. The advantages of the algorithms given in Wang \& Engel (1998) are the minimum number of parameters that must be determined as compared to other forms of the Beta function. These predictions are compared to predictions from the CERES-Wheat V3.0 (CW3) model and from data collected from field experiments. Data used in this study were from different locations in Nebraska. However, these results have a wider applicability to winter wheat regions of the central and northern Great Plains of the US and to wheat-growing locations around the world with similar environments. 


\section{MATERIALS AND METHODS}

\subsection{Field experiment}

A 3 yr field experiment was conducted at the Havelock Farm, Department of Agronomy and Horticulture, University of Nebraska-Lincoln $\left(40^{\circ} 51^{\prime} \mathrm{N}, 96^{\circ} 36^{\prime} \mathrm{W}\right.$, elevation $347 \mathrm{~m})$, during the 1996-97 (1997), 1997-98 (1998) and 1998-99 (1999) growing seasons. 3 semidwarf, hard red winter wheat cultivars - Arapahoe, Karl 92, and NE92458-were used in the first 2 seasons. Problems were encountered at sowing for the cultivar NE92458, so only the cultivars Arapahoe and Karl 92 were used in the 1999 growing season. In each growing season, the cultivars were planted on 2 sowing dates. The early sowing dates for the 3 seasons were 4 October 1996, 1 October 1997 and 1 October 1998. The later sowing dates were 15 October 1996, 15 October 1997 and 12 October 1998. To avoid confounding effects of disease, the plots were sprayed with the fungicide Tilt (1-[[2-(2,4dichlorophenyl)-4-propyl-1,3-dioxland-2-yl]methyl-1H$1,2,4$ triozole; Novartis) at heading.

The plots were $1.2 \mathrm{~m}$ wide and $2.4 \mathrm{~m}$ long with a $0.30 \mathrm{~m}$ row spacing. The planting density was $65 \mathrm{~kg}$ $\mathrm{ha}^{-1}$ for all the 3 seasons. There were 4 rows in each plot in an east-west row direction in 1997 and 1998, and a north-south row direction in 1999. These plots were surrounded by other wheat plots extending at least $50 \mathrm{~m}$ in all directions. The plants were grown under rainfed conditions. The soil at the experimental site was a Butler silt loam (fine, montmorillonitic, mesic Abruptic Agriaquoll; USDA taxonomy).

The dates of major visible phenological stages were determined either every $3 \mathrm{~d}$ or, when near a transition from one stage to another, every day. The following stages were recorded based on the Zadoks scale (ZS; Zadoks et al. 1974); booting (BT, ZS = 41), heading (HD, $\mathrm{ZS}=58)$, anthesis (AN, ZS = 65), and physiological maturity ( $\mathrm{MA}, \mathrm{ZS}=92)$. The double ridge (DR) and terminal spikelet initiation (TS) stages were determined by destructive sampling of 1 or 2 plants per plot ( 3 replicates for each cultivar) every 2 to $3 \mathrm{~d}$ during the appropriate time intervals. The main stem samples were dissected, and the dates of DR and TS occurrence were recorded. When recording the dates of DR and TS, the dissected main stem apex was observed with a microscope based on the standard from Porter et al. (1987).

An automated weather station at the field site was used to collect hourly meteorological data (Campbell Scientific, Logan, UT) during the 1997 and 1998 growing seasons. During the 1999 growing season, the hourly meteorological data were from an automated weather station located about $200 \mathrm{~m}$ from the field site. The wind and radiation sensors were $3 \mathrm{~m}$ and the air temperature and humidity sensors were $2 \mathrm{~m}$ above ground.

\subsection{Prediction of phenological development}

A nonlinear multiplicative model (WE) (Wang \& Engel 1998) and the phenological development subroutine from CW3 (Ritchie 1991, Jones et al. 1994) were used to predict phenological development of the 3 winter wheat cultivars. The entire CW3 was run for each season, but only the phenology data were used in this study.

\subsubsection{WE model}

The general form of the WE model is:

$$
r=R_{\max } f(T) f(P) f(V)
$$

where $r$ is the daily development rate $\left(\mathrm{d}^{-1}\right) ; R_{\max }$ is the maximum development rate $\left(\mathrm{d}^{-1}\right)$; and $f(T), f(P)$ and $f(V)$ are the temperature, photoperiod, and vernalization response functions, respectively (dimensionless, with values between 0 and 1). The rate $r$ is calculated differently for the vegetative (EM to $A N)$ and the reproductive phases (AN to MA). All response functions in Eq. (1) were used to calculate $r$ in the vegetative phase. For the reproductive phase, $r$ is based only on temperature, i.e. $r=R_{\max , \mathrm{r}} f(T)$, where $R_{\max , \mathrm{r}}$ is maximum development rate for the reproductive phase. A similar function $R_{\mathrm{max}, \mathrm{v}}$ exists for the vegetative stage. After $r$ was determined the accumulated development rate $(R=\Sigma r)$ was calculated; $\mathrm{R}=0$ at $\mathrm{EM}, \mathrm{R}=1$ at $\mathrm{AN}$, and $\mathrm{R}=2$ at $\mathrm{MA}$.

Following Wang \& Engel (1998), $f(T)$ was defined as:

$$
\begin{gathered}
f(T)=\frac{2\left(T-T_{\min }\right)^{\alpha}\left(T_{\mathrm{opt}}-T_{\min }\right)^{\alpha}-\left(T-T_{\min }\right)^{2 \alpha}}{\left(T_{\mathrm{opt}}-T_{\min }\right)^{2 \alpha}} \\
\alpha=\frac{\ln 2}{\ln \left[\left(T_{\max }-T_{\min }\right) /\left(T_{\mathrm{opt}}-T_{\min }\right)\right]}
\end{gathered}
$$

where $T$ was the daily mean air temperature $\left({ }^{\circ} \mathrm{C}\right)$ and different values of the cardinal temperatures $T_{\min }, T_{\text {opt }}$, and $T_{\max }$ (minimum, optimum, and maximum temperatures) were used for the vegetative and reproductive phases. The $T_{\min }, T_{\text {opt }}$, and $T_{\max }$ used for the vegetative phase in this study were 0,24 , and $35^{\circ} \mathrm{C}$ and for the reproductive phase 8,29 , and $40^{\circ} \mathrm{C}$, respectively (Wang \& Engel 1998, Porter \& Gawith 1999). It was assumed that there were no differences in temperature response among the cultivars.

The photoperiod response function, $f(P)$, used in this simulation was:

$$
f(P)=1-\exp \left[-\omega\left(P-P_{\mathrm{c}}\right)\right]
$$

where $P$ is the actual photoperiod $(\mathrm{h}), P_{\mathrm{c}}$ is critical photoperiod (h) below which no phenological development occurs, and $\omega\left(\mathrm{h}^{-1}\right)$ is a photoperiod sensitivity parameter related to each cultivar. 
The vernalization response function, $f(V)$, was determined by:

$$
f(V)=\min \left\{1, \max \left[0,\left(V_{\mathrm{n}}-V_{\mathrm{nb}}\right) /\left(V_{\mathrm{nd}}-V_{\mathrm{nb}}\right)\right]\right\}
$$

where $V_{\mathrm{n}}$ are the accumulated vernalization days, $V_{\text {nd }}$ is the number of days required for a plant to be completely vernalized (the vernalization requirement), and $V_{\mathrm{nb}}$ is the minimum number of days after emergence before vernalization affects the rate of phenological development (base vernalization days).

$V_{\mathrm{n}}$ was calculated from germination as:

$$
V_{\mathrm{n}}=\sum f \mathrm{v}_{\mathrm{n}}(T)
$$

where the daily vernalization response, $f \mathrm{v}_{\mathrm{n}}(T)$, was based on cardinal temperatures for vernalization ( $T_{\min , \mathrm{vn},} T_{\mathrm{opt}, \mathrm{vn},}$ and $\left.T_{\text {max,vn }}\right)$ using Eq. (2). The $T_{\min , \mathrm{vn}}$, $T_{\text {opt,vn, }}$ and $T_{\text {max,vn }}$ values were $-1,2$, and $15^{\circ} \mathrm{C}$ (Wang \& Engel 1998). Both $V_{\text {nb }}$ and $V_{\text {nd }}$ vary with cultivar. In this study, $V_{\text {nd }}$ values were $46 \mathrm{~d}$ for Arapahoe, and $40 \mathrm{~d}$ for Karl 92 and NE92458 (Atak 1997). The value of minimum vernalization days $\left(V_{\mathrm{nb}}\right)$ was assumed to be onefifth of $V_{\text {nd }}$ (Ritchie 1991, Cao \& Moss 1997, Wang \& Engel 1998).

The observed phenological data from all 3 growing seasons ( 2 data sets in each season) were used to test the model. To test the phenological data from the 1997 and 1998 seasons, the cross-validation method was used (Gauch 1988). In the cross-validation method, if there are $n$ sets of data in a study, the $(n-1)$ sets were used to estimate the parameters, and one set was used as independent data to test the model. In addition, since the plants were exposed to different weather conditions during their life cycle, the resulting parameters would be representative of a wider range of conditions than using a single sowing date to establish these parameters. In this way, all treatments could be tested. Data from the 1999 season were not used to estimate any parameters and were an independent data set.

Three other independent data sets were also used to evaluate the predictions of phenological development. Two data sets from the Nebraska Intrastate Wheat Trial (authors' unpubl. data) in eastern Nebraska for the growing seasons from 1991-92 to 1993-94, and 1995-96 in Lincoln $\left(40^{\circ} 51^{\prime} \mathrm{N}, 96^{\circ} 36^{\prime} \mathrm{W}, 347 \mathrm{~m}\right)$ and from $1992-93$ to $1995-96$ in Mead $\left(41^{\circ} 15^{\prime} \mathrm{N}, 96^{\circ} 35^{\prime} \mathrm{W}\right.$, $366 \mathrm{~m}$ ) were used to test the predictions of anthesis date for the 3 cultivars. These locations represent a subhumid climate. The third data set was from a semiarid climate (Xu 1996), Sidney, NE $\left(41^{\circ} 13^{\prime} \mathrm{N}\right.$, $\left.103^{\circ} 1^{\prime} \mathrm{W}, 1317 \mathrm{~m}\right)$ in western Nebraska, for the 1992-93 (1993) and 1993-1994 (1994) growing seasons and was used to predict the heading and maturity dates for the cultivar Arapahoe. The daily meteorological data necessary to run the WE model and CW3 were obtained from the automated weather stations near the 3 experimental sites.

Three parameters-maximum development rate $\left(R_{\max }\right)$, photoperiod sensitivity $(\omega)$, and critical photoperiod $\left(P_{\mathrm{C}}\right)$ - were needed for each cultivar in order to calculate $r$ in Eq. (1). The SAS-NLIN (SAS Institute 1989) procedure with the Marquardt method was used to estimate these parameters using the observed phenological data (as explained above), daily mean air temperature $(T)$, and photoperiod $(P)$. Daily mean air temperature was calculated as the average of measured hourly temperatures. The photoperiod, including civil twilight (when the sun is $6^{\circ}$ below the horizon), was calculated using algorithms from the Almanac for Computers (United States Naval Observatory 1990). The values of $R_{\text {max, }}, \omega$, and $P_{\mathrm{c}}$ for the vegetative phase for the 3 cultivars are shown in Table 1. For the reproductive phase, only 1 parameter, $R_{\text {max,r, }}$ is needed, and it was found to be $0.04545 \mathrm{~d}^{-1}$ for the 3 cultivars. The SAS-NLIN iteration procedure used in this study was similar to the Simplex method used in other studies to estimate parameters of this nature (Sinclair et al. 1991, Yin et al. 1997). The iteration procedure in the Simplex method and the SAS-NLIN procedure in this study only minimizes the residual sum of squares (RSS) for Eq. (1) regardless of convergence (Sinclair et al. 1991, Yin et al. 1997). Therefore, there were no standard errors for these parameter estimates. The SAS-NLIN procedure was used because it resulted in a smaller error (RSS $<0.05)$ than the Simplex method (RSS $<3$ ). The $R$ values for predicting the intermediate phenological stages were based on Table 4 of Wang \& Engel (1998) and measured values in our field experiment. The $R$ values for DR, TS, BT and HD were $0.20,0.40,0.70$, and 0.92 , respectively. These values correspond closely with those given in Wang \& Engel (1998).

\subsubsection{CW3 model}

In CW3, the major phenological stages were simulated based on the TT approach. The photoperiod and vernalization effects were only considered during the period from EM to TS. To quantify the genotypic variation in phenological development, 3 dimensionless coefficients are needed. They are a vernalization coefficient (P1V), a photoperiod coefficient (P1D), and a coefficient related to the length of the grain filling period (P5). The phyllochron (PHINT, ${ }^{\circ} \mathrm{C} \mathrm{d} \mathrm{leaf}{ }^{-1}$ ) is needed for predicting stages after emergence and the default value of PHINT is set as 95, which is a good estimate in the absence of data (Ritchie 1991). The observed anthesis and maturity data in 1998 growing season were used to calculate the cultivar coeffi- 
cients, P1D and P5 using DSSAT (V3.0) Genotype Coefficient Calculator (GenCalc) (Hunt \& Pararajasingham 1994). The measured PHINT value in the 1998 season is the same as the default value $\left(95^{\circ} \mathrm{d}\right.$ leaf ${ }^{-1}$ ). There were optimal environmental conditions in this growing season and the plants were never under stress. Data from 1 growing season are sufficient to run GenCalc (Hunt \& Pararajasingham 1994, Tubiello et al. 1999). The phenological stages after TS is strictly related to temperature in CW3. It takes 3 phyllochrons from TS to BT, 2 phyllochrons from BT to $\mathrm{HD}$, and $200^{\circ} \mathrm{C}$ d from HD to AN. The physiological maturity (MA) is determined by TT and coefficient P5 (Ritchie 1991).

The resulting values for P1D were 3.25 for Arapahoe, 2.35 for Karl 92 and 2.90 for NE92458. The P5 values were 3.05 for Arapahoe, 2.00 for Karl 92 and 2.65 for NE92458. The coefficient related to vernalization (P1V) is normally obtained from greenhouse experiments (Ritchie 1991). The P1V values for the 3 cultivars in this study were estimated from a greenhouse experiment (Atak 1997). The P1V value for Arapahoe was 6.00 and 4.00 for Karl 92 and NE92458. The estimated coefficients were then used to predict phenological stages in the 1997 and 1999 growing seasons.

Table 1. Maximum development rate for vegetative phase $\left(R_{\text {max }, \mathrm{v}}\right)$, photoperiod sensitivity $(\omega)$, and critical photoperiod $\left(P_{\mathrm{c}}\right)$ for predicting phenological stages in the vegetative phase using the WE model for 3 genotypes of winter wheat Triticum aestivum

\begin{tabular}{|lccc|}
\hline Genotype & $\begin{array}{c}R_{\max , \mathrm{v}} \\
\left(\mathrm{d}^{-1}\right)\end{array}$ & $\begin{array}{c}\omega \\
\left(\mathrm{h}^{-1}\right)\end{array}$ & $\begin{array}{c}P_{\mathrm{c}} \\
(\mathrm{h})\end{array}$ \\
\hline Arapahoe & 0.0294 & 0.3400 & 9.5 \\
Karl 92 & 0.0349 & 0.1649 & 7.0 \\
NE92458 & 0.0350 & 0.1829 & 8.0 \\
\hline
\end{tabular}

\subsection{Data analysis}

Analysis of variance for the day of year (DOY) of different stages among years, sowing dates and cultivars was performed using the SAS general linear procedure (SAS Institute 1989). The LSD at a level of 0.05 was used to compare the means.

The model performance for predicting phenological development against observed values was tested using the root mean square error (RMSE). The RMSE was calculated as:

$$
\operatorname{RMSE}=\left(\frac{\sum_{i=1}^{n}\left(\mathrm{OBS}_{i}-\mathrm{PRED}_{i}\right)^{2}}{n}\right)^{1 / 2}
$$

where $\mathrm{OBS}_{i}$ and $\mathrm{PRED}_{i}$ are the observed and predicted date of a phenological stage and $n$ is the number of $\mathrm{OBS}_{i}: \mathrm{PRED}_{i}$ pairs. A small value of the RMSE suggests a close agreement between predicted and observed values. In addition, linear regression was also used to compare observed and predicted values of phenological development.

The climatic and phenological data can be obtained from the corresponding author for verification.

\section{RESULTS}

There was a large variation in environmental conditions in the 3 growing seasons. In the 1997 season, the air temperature was lower than the $30 \mathrm{yr}$ average during most of the months. The 1998 and 1999 seasons were warmer as compared to the $30 \mathrm{yr}$ average during the period from December to March. In most months, except March and June, mean air temperature in 1998 and 1999 was higher than that in 1997 (Table 2). The period from October to February 1999 had the highest

Table 2. Monthly mean air temperature $\left(T_{\text {air }}\right)$ and total monthly precipitation (Precip) for 3 growing seasons, and 30 yr mean

\begin{tabular}{|c|c|c|c|c|c|c|c|c|}
\hline \multirow[t]{2}{*}{ Month } & \multicolumn{2}{|c|}{1997} & \multicolumn{2}{|c|}{1998} & \multicolumn{2}{|c|}{1999} & \multicolumn{2}{|c|}{30 yr mean } \\
\hline & $\begin{array}{l}T_{\text {air }} \\
\left({ }^{\circ} \mathrm{C}\right)\end{array}$ & $\begin{array}{l}\text { Precip } \\
(\mathrm{mm})\end{array}$ & $\begin{array}{l}T_{\text {air }} \\
\left({ }^{\circ} \mathrm{C}\right)\end{array}$ & $\begin{array}{l}\text { Precip } \\
(\mathrm{mm})\end{array}$ & $\begin{array}{l}T_{\text {air }} \\
\left({ }^{\circ} \mathrm{C}\right)\end{array}$ & $\begin{array}{l}\text { Precip } \\
(\mathrm{mm})\end{array}$ & $\begin{array}{l}T_{\text {air }} \\
\left({ }^{\circ} \mathrm{C}\right)\end{array}$ & $\begin{array}{l}\text { Precip } \\
\text { (mm) }\end{array}$ \\
\hline Oct & 11.8 & 17 & 12.5 & 85 & 13.5 & 68 & 12.9 & 44 \\
\hline Nov & 0.8 & 88 & 2.3 & 59 & 6.7 & 74 & 3.9 & 23 \\
\hline Dec & -4.5 & 6 & -1.1 & 18 & 0.1 & 5 & -2.6 & 21 \\
\hline Jan & -6.1 & 9 & -3.2 & 33 & -4.4 & 16 & -5.3 & 12 \\
\hline Feb & -1.0 & 23 & 2.6 & 18 & 3.0 & 31 & -2.7 & 24 \\
\hline Mar & 6.0 & 20 & 1.1 & 86 & 4.6 & 22 & 3.1 & 37 \\
\hline Apr & 7.6 & 90 & 10.9 & 59 & 10.5 & 136 & 10.7 & 54 \\
\hline May & 14.4 & 60 & 19.4 & 145 & 17.0 & 149 & 16.7 & 95 \\
\hline Jun & 22.9 & 75 & 21.4 & 147 & 21.3 & 157 & 21.8 & 150 \\
\hline Mean/Total & 5.7 & 388 & 7.3 & 650 & 8.0 & 658 & 6.5 & 459 \\
\hline
\end{tabular}


monthly air temperature except for January, while 1997 had the lowest monthly air temperature for the same period (Table 2). The 1998 and 1999 growing seasons had more precipitation (650 and $658 \mathrm{~mm}$ ) than the $30 \mathrm{yr}$ average $(459 \mathrm{~mm})$, while the 1997 season had less precipitation $(388 \mathrm{~mm}$ ) than the $30 \mathrm{yr}$ average. The large differences in precipitation between the 1997 and the 1998 and 1999 growing seasons occurred during the fall (October and November) and the period from March to June, especially during the grain-filling period (middle of May to the end of June).

There were large differences in phenological development among the cultivars in the 3 growing seasons. In general, plants in 1997 developed more slowly, and the major phenological stages occurred later than those in the other 2 seasons (Table 3). Because of a warm growing season in 1999, the occurrence of DR varied from DOY 79 to 98 and was earlier than observations in 1997, which varied between DOY 90 and 111. In the 3 growing seasons, the mean DOY for AN and MA for the 3 cultivars were 154 and 180 in 1997, 142 and 175 in 1998, and 146 and 180 in 1999 (Table 3). In each season, the occurrence of major phenological stages in the cultivars Karl 92 and NE92458 was earlier than those in Arapahoe. The major variation in phenol- ogy among the cultivars was observed during the period from planting to TS, where Karl 92 and NE92458 had earlier occurrences of DR and TS than Arapahoe. Plants in 1997 had a shorter grain-filling period (the difference between MA and AN, 27 d) than those in 1998 and 1999 ( $>30 d_{\text {i }}$ Table 3) because this period was warmer in 1997 than in the other 2 years (Table 2). Among the different phenological stages, the observed range in DR and TS was larger (4 to $11 \mathrm{~d}$ ) than the later stages $(<4$ d) (Table 3$)$. The variation in predicted DOY for different phenological stages using the 2 models showed a similar trend to that for the observed DOY for phenological stages (Table 3).

RMSE for predicting the different phenological stages averaged over 3 cultivars using the 2 models are shown in Table 4 . In all the 3 seasons, the WE model predicted $\mathrm{BT}, \mathrm{HD}, \mathrm{AN}$, and MA better than DR and TS, as anticipated by McMaster et al. (1992). The best prediction of the WE model was for MA, a mean RMSE of $2.9 \mathrm{~d}$. If the actual date of anthesis was used instead of the modeled date, the RMSE for this prediction would have been $1.1 \mathrm{~d}$. The mean RMSE values for DR and TS were 7.3 and $7.1 \mathrm{~d}$. The mean RMSE values for CW3 were greater than those for the WE model for all phenological stages except TS. As the season pro-

Table 3. Observed and predicted day of year (DOY) using the Wang \& Engel (WE) and CERES-Wheat V3.0 (CW3) models for double ridge (DR), terminal spikelet (TS), booting (BT), heading (HD), anthesis (AN), and maturity (MA) in 3 winter wheat growing seasons for the 3 cultivars on 2 sowing dates (Sow) in Lincoln, NE. Phenological stages predicted by CW3 model are not included, because observed phenological data were used to calibrate the model. Numbers in parenthesis: range of observed phenological stages (d). LSD: least significant difference

\begin{tabular}{|c|c|c|c|c|c|c|c|c|c|c|c|c|c|c|c|c|c|c|}
\hline \multirow[t]{2}{*}{ Sow } & \multirow[t]{2}{*}{ Genotype } & \multicolumn{6}{|c|}{ Observed DOY } & \multicolumn{11}{|c|}{ - Predicted DOY } \\
\hline & & DR & TS & BT & $\mathrm{HD}$ & AN & MA & $\begin{array}{l}\mathrm{DR} \\
\mathrm{WE}\end{array}$ & \multicolumn{2}{|c|}{ TS } & \multicolumn{2}{|c|}{$\mathrm{BT}$} & \multicolumn{2}{|c|}{ HD } & \multicolumn{2}{|c|}{$\begin{array}{c}\text { AN } \\
\text { WE CW3 }\end{array}$} & \multicolumn{2}{|c|}{$\begin{array}{c}\text { MA } \\
\text { WE CW3 }\end{array}$} \\
\hline \multicolumn{19}{|l|}{1997} \\
\hline \multirow{3}{*}{$1 \mathrm{st}$} & Arapahoe & $91(7)$ & $117(8)$ & $138(3)$ & $150(3)$ & $154(3)$ & $179(3)$ & 91 & 117 & 117 & 136 & 135 & 146 & 151 & 150 & 153 & 177 & 183 \\
\hline & Karl 92 & $90(8)$ & $113(6)$ & $136(2)$ & $145(2)$ & $152(2)$ & $177(1)$ & 89 & 115 & 109 & 135 & 132 & 145 & 145 & 149 & 151 & 177 & 181 \\
\hline & NE92458 & $92(6)$ & $115(6)$ & $138(2)$ & $147(3)$ & 153(3) & $179(2)$ & 90 & 116 & 108 & 136 & 132 & 145 & 150 & 150 & 149 & 177 & 180 \\
\hline \multirow[t]{3}{*}{ 2nd } & Arapahoe & $111(6)$ & $124(5)$ & $141(2)$ & $152(3)$ & $157(1)$ & $182(3)$ & 92 & 118 & 107 & 138 & 139 & 149 & 152 & 152 & 154 & 178 & 182 \\
\hline & Karl 92 & $107(5)$ & $118(5)$ & $137(2)$ & $146(3)$ & $154(1)$ & $179(2)$ & 89 & 113 & 110 & 134 & 134 & 144 & 146 & 148 & 151 & 176 & 180 \\
\hline & NE92458 & $110(6)$ & $120(4)$ & $139(2)$ & 151(3) & $155(2)$ & 181(3) & 90 & 116 & 111 & 136 & 136 & 145 & 149 & 149 & 151 & 176 & 181 \\
\hline \multicolumn{19}{|l|}{1998} \\
\hline \multirow[t]{3}{*}{$1 \mathrm{st}$} & Arapahoe & $91(6)$ & $109(6)$ & 131(5) & 139(3) & $143(2)$ & $177(1)$ & 101 & 118 & & 135 & & 144 & & 148 & & 180 & \\
\hline & Karl 92 & $88(7)$ & $102(5)$ & $123(3)$ & 134(1) & 139(1) & $172(2)$ & 99 & 114 & & 133 & & 142 & & 146 & & 179 & \\
\hline & NE92458 & $90(7)$ & $104(7)$ & $125(4)$ & $135(2)$ & $139(2)$ & $174(3)$ & 100 & 116 & & 134 & & 143 & & 147 & & 179 & \\
\hline \multirow[t]{3}{*}{ 2nd } & Arapahoe & $101(4)$ & $114(7)$ & 133(2) & $142(1)$ & $146(1)$ & $179(2)$ & 101 & 116 & & 134 & & 143 & & 147 & & 179 & \\
\hline & Karl 92 & $97(5)$ & $107(5)$ & $127(4)$ & $137(3)$ & $140(2)$ & $174(2)$ & 100 & 115 & & 134 & & 143 & & 147 & & 179 & \\
\hline & NE92458 & $99(6)$ & $109(4)$ & $129(1)$ & $137(1)$ & $141(2)$ & $176(3)$ & 101 & 116 & & 134 & & 142 & & 147 & & 179 & \\
\hline \multicolumn{19}{|l|}{1999} \\
\hline \multirow[t]{2}{*}{$1 \mathrm{st}$} & Arapahoe & $87(7)$ & $103(7)$ & $132(3)$ & $144(2)$ & $148(2)$ & 180(1) & 91 & 114 & 99 & 134 & 125 & 144 & 137 & 148 & 141 & 179 & 174 \\
\hline & Karl 92 & $79(11)$ & $97(6)$ & $126(2)$ & 138(3) & $145(1)$ & $177(2)$ & 80 & 109 & 90 & 131 & 118 & 141 & 131 & 145 & 135 & 177 & 168 \\
\hline \multirow[t]{2}{*}{ 2nd } & Arapahoe & $98(6)$ & $105(7)$ & $134(3)$ & $146(2)$ & $150(2)$ & 182(1) & 91 & 114 & 102 & 134 & 128 & 144 & 139 & 148 & 142 & 179 & 175 \\
\hline & Karl 92 & $87(5)$ & $101(5)$ & $127(3)$ & $140(1)$ & $146(2)$ & $179(1)$ & 88 & 109 & 92 & 130 & 120 & 141 & 133 & 145 & 136 & 177 & 169 \\
\hline \multirow[t]{3}{*}{$\operatorname{LSD}(0.05)$} & Year & 4.6 & 1.4 & 1.9 & 1.3 & 1.2 & 1.0 & & & & & & & & & & & \\
\hline & Sow & 3.7 & 1.1 & 1.5 & 1.0 & 0.9 & 0.8 & & & & & & & & & & & \\
\hline & Genotype & 4.6 & 1.4 & 1.9 & 1.3 & 1.2 & 1.0 & & & & & & & & & & & \\
\hline
\end{tabular}


Table 4. Root mean square error (RMSE) for double ridge (DR), terminal spikelet (TS), booting (BT), heading (HD), anthesis (AN), and maturity (MA) using the Wang \& Engel (WE) model and CERES-Wheat V3.0 (CW3) for the 3 growing seasons and 2 sowing dates (Sow) in Lincoln, NE

\begin{tabular}{|lcrrrrrr|}
\hline Year & Sow & DR & TS & BT & HD & AN & MA \\
\hline WE & & & & & & & \\
1997 & 1st & 1.2 & 1.3 & 2.0 & 2.6 & 3.4 & 1.6 \\
& 2nd & 19.0 & 5.1 & 3.1 & 4.0 & 5.7 & 4.1 \\
1998 & 1st & 10.3 & 10.7 & 8.1 & 6.9 & 6.8 & 5.2 \\
& 2nd & 2.1 & 5.8 & 5.0 & 4.5 & 5.3 & 3.4 \\
1999 & 1st & 6.3 & 11.0 & 3.8 & 3.5 & 2.0 & 0.7 \\
& 2nd & 5.0 & 8.5 & 2.1 & 1.6 & 1.6 & 2.5 \\
Mean & & 7.3 & 7.1 & 4.0 & 3.9 & 4.1 & 2.9 \\
CW3 & & & & & & & \\
1997 & 1st & a & 4.7 & 4.5 & 1.8 & 2.6 & 2.9 \\
& 2nd & & 7.8 & 2.7 & 3.5 & 3.4 & 0.6 \\
1999 & 1st & & 5.7 & 7.5 & 7.0 & 8.6 & 7.6 \\
& 2nd & \multicolumn{7}{c}{6.7} & 6.5 & 7.0 & 9.1 & 8.6 \\
Mean & & 6.2 & 5.3 & 4.8 & 5.9 & 5.0 \\
a CW3 did not predict double ridge & & & \\
\hline
\end{tabular}

gressed beyond TS, the WE model was a better predictor of phenology than CW3, e.g. at MA the RMSE value for CW3 was $5.0 \mathrm{~d}$ (Table 4).

The predicted versus observed DOY of AN for the 3 cultivars at Lincoln and Mead, Nebraska, from the Nebraska Intrastate Wheat Trial data set is plotted in Fig. 1. For the WE model, the differences between observed and predicted days of anthesis ranged within \pm $7 \mathrm{~d}$, while for CW3 the differences were within $\pm 10 \mathrm{~d}$. Combining the 3 cultivars and 2 locations, $\mathrm{r}^{2}$ and RMSE were 0.91 and $3.9 \mathrm{~d}$ for the WE model and 0.65 and $4.7 \mathrm{~d}$ for CW3. The WE model tended to overestimate AN dates when plants reached AN early (between DOY 140 and 145). In contrast, CW3 predicted early AN dates better than later AN dates (Fig. 1).

The differences between observed and predicted HD dates for the data set from western Nebraska for the 1993 and 1994 growing seasons were -5 and $2 \mathrm{~d}$ for the WE model and -4 to $7 \mathrm{~d}$ for CW3. The 2 models overestimated the maturity date for the 1993 growing season, -11 and $-7 \mathrm{~d}$ for the WE model and CW3; however, both models accurately predicted the maturity dates in the 1994 season, a difference of 0 and $3 \mathrm{~d}$ for the WE model and CW3.

\section{DISCUSSION}

The WE model performed better than CW3 for predicting phenological stages between booting and maturity based on the field data collected in the 3 yr of this study and generally as well from the 3 additional

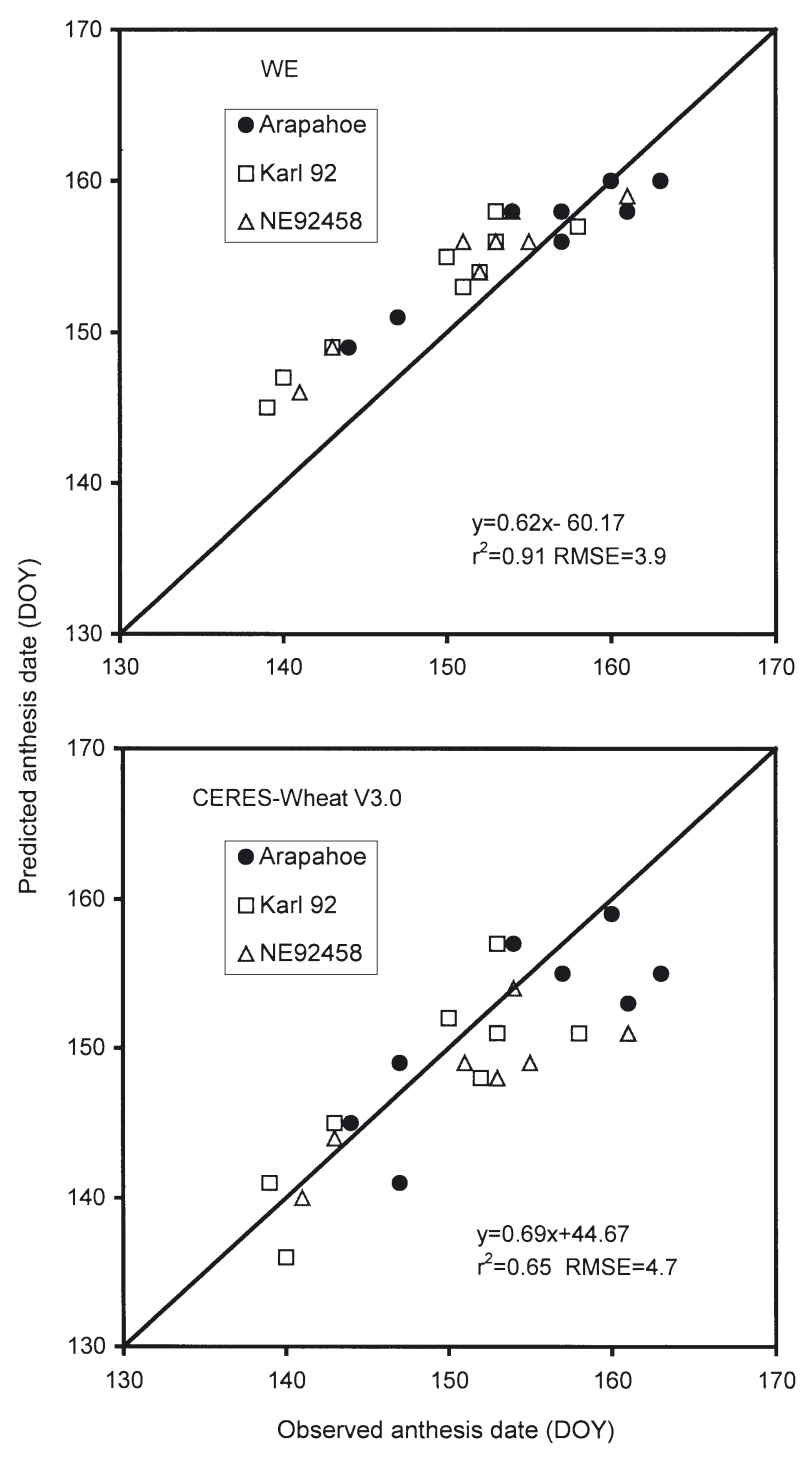

Fig. 1. Predicted vs observed anthesis date (DOY) using the Wang \& Engel (WE) model and CERES-Wheat V3.0 (CW3) for the 3 cultivars in the multiple-year field trial from 1991-92 to 1993-94, and 1995-96 in Lincoln, and from 1992-93 to 1995-96 in Mead, Nebraska. Each data point was an anthesis date for each cultivar at 1 location in 1 growing season. The diagonal is the 1:1 line

data sets. The mean RMSE ranged from 2.9 to $4.1 \mathrm{~d}$ and was the lowest for predicting maturity. For CW3, the mean RMSE ranged from 4.8 to $5.9 \mathrm{~d}$ for predicting phenological stages from booting to maturity. The WE model considers the interactive effects of temperature, photoperiod, and vernalization on phenological development in the vegetative phase (Wang \& Engel 1998). CW3 adjusts phenological development during the period of EM to TS based on vernalization and photoperiod effects and then utilizes the least favorable factor (Ritchie 1991). However, a number of studies have 
shown that vernalization and photoperiod interact to determine the response of plants to temperature toward AN in wheat (Davidson et al. 1985, Slafer \& Rawson 1994). The approach used in the WE model may represent a more realistic relationship between phenological development and environmental variables. Cao \& Moss (1997) used a similar approach to the WE model to predict DR, TS and HD in different wheat cultivars, the mean RMSE was $6 \mathrm{~d}$ for DR, $5 \mathrm{~d}$ for TS and $4 \mathrm{~d}$ for HD. McMaster et al. (1992) did not consider photoperiod and vernalization effects and used generic parameters for the different wheat cultivars in their study, the RMSE ranged 13.5 to $8.2 \mathrm{~d}$ for predicting JT, HD and MA.

The WE model predicted DR and both models predicted TS with a larger RMSE compared to the later phenological stages, particularly for the WE model (Table 4). One reason for the poor predictions of DR and TS with the WE model may be the representation of the vernalization response as a linear rather than a curvilinear relationship during the periods when vernalization is important, from EM to TS. Of the different algorithms available to model the effects of temperature, photoperiod, and vernalization on phenological development, there is a relative paucity of information on modeling vernalization. The WE model assumes a linear vernalization function which depends upon the number of days required for a plant to be completely vernalized (the vernalization requirement), the minimum number of days after emergence before vernalization affects the rate of phenological development (base vernalization days), and the current number of accumulated vernalization days (Weir et al. 1984, Wang \& Engel 1998). The vernalization response used in CW3 also uses a linear function (Ritchie 1991). Using final leaf number as a measure of the vernalization requirement, experimental evidence indicates a curvilinear relationship between final leaf number and accumulated vernalization days, rather than a linear relationship. The curve becomes asymptotic to the final leaf number as the vernalization requirement is met (Brookings 1996, Fowler et al. 1996). The application of a curvilinear vernalization function may improve the predictions of DR and TS. Another problem with accurately predicting these stages, aside from the destructive sampling technique, is that the plants can remain at the DR stage for a relatively long period of time depending on the weather conditions, an observation we have noted in the field. Thus, depending upon sampling frequency and weather conditions, it is possible that predictions and observations of DR, and therefore TS, could be in good agreement or poor agreement (Table 4). Weir et al. (1984) noted that the period from EM to DR can, at best, be measured with an accuracy of only 3 to $4 \mathrm{~d}$ and with the model AFR-
CWHEAT1 simulations of this period varied from 2 to $10 \mathrm{~d}$.

Both models consider cultivar differences in vernalization and photoperiod responses. Among the 3 cultivars, Arapahoe required the longest time to be fully vernalized and was more sensitive to photoperiod than Karl 92 and NE92458. The maximum development rate during vegetative phase $\left(R_{\max , v}\right)$, in the WE model, differed among the cultivars in this study. The maximum development rate $\left(R_{\max }\right)$ has a physiological meaning (Wang \& Engel 1998). The reciprocal of $R_{\max }(D=$ $\left.1 / R_{\max }\right)$ represents the minimum duration of the vegetative $\left(D_{\mathrm{v}}\right)$ phase under optimal environmental conditions. The $D_{\mathrm{v}}$ values ranged from 29 to $34 \mathrm{~d}$ among the 3 cultivars. The $D_{\mathrm{v}}$ values were also found to be different in rice cultivars (Yin et al. 1997). Similarly, the minimum duration of the reproductive phase $\left(D_{\mathrm{r}}\right)$ is inversely related to the maximum development rate for this phase. The $D_{\mathrm{r}}$ values were the same for all 3 cultivars in this study $(22 \mathrm{~d})$. This constant $D_{\mathrm{r}}$ value should not be generalized to other cultivars. Wang \& Engel (1998) used a constant $D_{\mathrm{v}}$ value (38 d, from Angus et al. 1981) and different $D_{\mathrm{r}}$ values for the winter wheat cultivars used in their study.

CW3 requires 3 genetic coefficients (P1V, P1D, and P5) to simulate phenology. These coefficients are usually obtained from field experiments under nearoptimum conditions in conjunction with Gencalc (Hunt \& Pararajasingham 1994) or from published values. However, the latter approach must be used with caution, as these coefficients may change with location for the same cultivar, and the former approach is preferable. The WE model requires 5 coefficients to simulate phenology: $R_{\max }$ for both the vegetative and reproductive phases (assuming the cardinal temperatures are the same for all cultivars, which is a reasonable assumption given the data in Porter \& Gawith 1999); $V_{\text {nd, }}$, the number of days required for a plant to be completely vernalized (which varies from 40 to $50 \mathrm{~d}$ for modern winter wheat cultivars), the photoperiod sensitivity $(\omega)$ and the critical photoperiod $\left(P_{\mathrm{c}}\right)$. As a first estimate to determining the coefficients for the WE model, the following approach can be employed. If the values of $R_{\max }$ for a known cultivar have been determined, values for other cultivars can be obtained by discussions with a plant breeder based on comparisons of the EM-AN and AN-PM periods for the known and unknown cultivars. Plant breeders generally compare hundreds of lines in field trials under different environments. This type of information should be readily available. Then, by adjusting the value of the unknown $R_{\max }$ to account for these differences in time relative to the known $R_{\max }$ a reasonably accurate value of $R_{\max }$ for an unknown cultivar can be obtained without growing it. If one assumes that the vernalization 
requirement of an unknown cultivar is $45 \mathrm{~d}$, then the result in the prediction of phenology, in the EM-TS period, will probably be very small. In order to establish values for the photoperiod-related coefficients, an approach similar to determining $R_{\max }$ can be used, where values for a known cultivar are manipulated to agree with a plant breeder's observations. Alternatively, detailed field observations of phenology in conjunction with the statistical procedures employed in this study can be used to determine the coefficients for the WE model. It would be expected that a 5 -variable model (WE) would be superior to a 3-variable model (CW3) in a statistical sense. However, a better representation of the interactions between temperature, photoperiod, and vernalization in the WE model may also contribute to its superiority over CW3.

\section{CONCLUSIONS}

The nonlinear WE model was a better predictor of the phenological stages from BT to MA than CW3 in this study. The WE model may be more realistic, as it considers the interactions between temperature, photoperiod and vernalization in the vegetative phase. However, both models predicted TS with larger RMSE values as compared with the later phenological stages, as did the WE model for predicting DR. These larger RMSE values associated with the DR and TS stages suggest that further research is needed to develop improved algorithms of the processes associated with these phenological stages. CW3 is used in many studies related to policy issues, such as climate change (Tubiello et al. 1995, Mearns et al. 1999, Ghaffari et al. 2001), and thus an effort to modify the phenology subroutine of CW3 may be appropriate, given the potential impact of phenology on yield and biomass predictions. The results of this study are applicable to the winter wheat regions of the central and northern Great Plains of the US and other locations in the world with a similar environment, where winter wheat is grown.

Acknowledgements. Drs. W. W. Wilhelm, T. J. Arkebauer, J. L. Lindquist, and G. S. McMaster reviewed an earlier version of this manuscript, and their constructive comments are appreciated. This article was published as paper 12941, Nebraska Agricultural Research Division.

\section{LITERATURE CITED}

Angus JF, Mackenzie DH, Morton R, Schafer CA (1981) Phasic development in field crops. II. Thermal and photoperiodic responses of spring wheat. Field Crops Res 4:269-283

Atak M (1997) Photoperiod, vernalization, and seeding rate effects on anthesis date and agronomic performance of winter wheat. MS thesis, University of Nebraska-Lincoln
Brooking IR (1996) Temperature response of vernalization in wheat: a developmental analysis. Ann Bot 78:507-512

Cao W, Moss DN (1997) Modelling phasic development in wheat: a conceptual integration of physiological components. J Agric Sci 129:163-172

Davidson JL, Christian KR, Jones DB, Bremner PM (1985) Response of wheat to vernalization and photoperiod. Aust J Agric Res 36:347-359

Fowler DB, Limin AE, Wang SY, Ward RW (1996) Relationship between low-temperature tolerance and vernalization response in wheat and rye. Can J Plant Sci 76:37-42

Gauch HG (1988) Model selection and validation for yield trial with interaction. Biometrics 44:705-715

Ghaffari A, Cook HF, Lee HC (2001) Simulating winter wheat yields under temperature conditions: exploring different management scenarios. Eur J Agron 15:231-240.

Horie T (1994) Crop ontogeny and development. In: Boote KJ (ed) Physiology and determination of crop yield. American Society of Agronomy (ASA), Crop Science Society of America (CSSA) and Soil Science Society of America (SSSA), Madison, WI, p 153-180

Hunt LA, Pararajasingham S (1994) Genotype coefficient calculator. In: Tsuji GY, Uehara G, Baka S (eds) DSSAT v3, Vol 3-4. University of Hawaii, Honolulu, p 203-233

Jones JW, Hunt LA, Hoogenboom G, Godwin DC and 8 others (1994) Input and output files. In: Tsuji GY, Uehara G, Baka S (eds) DSSAT v3, Vol 2-1. University of Hawaii, Honolulu

Kirby EJM, Weightman RM (1997) Discrepancies between observed and predicted growth stages in wheat. J Agric Sci 129:379-384

McMaster GS, Wilhelm WW, Morgan JA (1992) Simulating winter wheat shoot apex phenology. J Agric Sci 119:1-12

Mearns LO, Mavromatis T, Tsvetsinskaya E, Hays C, Easterling W (1999) Comparative responses of EPIC and CERES crop models to high and low spatial resolution climate change scenarios. J Geophys Res 104:6623-6646

Perry MW, Siddique KHM, Wallace JF (1987) Predicting phenological development of Australian wheats. Aust J Agric Res 38:809-819

Porter JR, Gawith M (1999) Temperatures and the growth and development of wheat: a review. Eur J Agron 10:23-36

Porter JR, Kirby EJM, Day W, Adam JS and 16 others (1987) An analysis of morphological development stages in Avalon winter wheat crops with different sowing dates and at ten sites in England and Scotland. J Agric Sci 109: 107-121

Rawson HM (1993) Prediction of heading time in wheat grown under high temperatures: effects of temperature, vernalisation and photoperiod. Indian J Plant Physiol 36: 239-245.

Ritchie JT (1991) Wheat phasic development. In: Hanks RJ, Ritchie JT (eds) Modeling plant and soil systems. American Society of Agronomy (ASA), Crop Science Society of America (CSSA) and Soil Science Society of America (SSSA), Madison, WI, p 31-54

Robertson GW (1968) A biometeorological time scale for a cereal crop involving day and night temperature and photoperiod. Int J Biometeorol 12:191-223

Saarikko RA, Carter TR (1996) Phenological development in spring cereals: response to temperature and photoperiod under northen conditions. Eur J Agron 5:59-70

SAS Institute (1989) SAS-STAT, users guide, ver. 6, 4th edn. SAS Institute, Cary, NC

Shaykewich CF (1995) An appraisal of cereal crop phenology modelling. Can J Plant Sci 75:329-341

Sinclair TR, Kitani S, Hinson K, Bruniard J, Horie T (1991) 
Soybean flowering date: linear and logistic models based on temperature and photoperiod. Crop Sci 31:786-790

Slafer GA, Rawson HM (1994) Sensitivity of wheat phasic development to major environmental factors: a re-examination of some assumptions made by physiologists and modellers. Aust J Plant Physiol 21:393-426

Slafer GA, Rawson HM (1995) Base and optimum temperatures vary with genotype and stage of development in wheat. Plant Cell Environ 18:671-679

Summerfield RJ, Roberts EH, Ellis RH, Lawn RJ (1991) Towards the reliable prediction of time to flowering in six annual crops. I. The development of simple models for fluctuating field environments. Exp Agric 27:11-31

Tubiello FN, Rosenzweig C, Volk T (1995) Interactions of $\mathrm{CO}_{2}$, temperature and management practices: simulations with a modified version of CERES-Wheat. Agric Syst 49: $135-152$

Tubiello FN, Rosenzweig C, Kimball BA, Pinter PJ Jr, Wall GW, Hunsaker DJ, LaMorte RL, Garcia RL (1999) Testing CERES-Wheat with free-air carbon dioxide enrichment (FACE) experiment data: $\mathrm{CO}_{2}$ and water interactions. Agron J 91:247-255

United States Naval Observatory (1990) Almanac for computers. Nautical Almanac Office, United States Naval Observatory, Washington, DC

Wang EL, Engel T (1998) Simulation of phenological development on wheat crops. Agric Syst 58:1-24

Editorial responsibility: Andrew Comrie, Tucson, Arizona, USA
Wang SY, Ward RW, Ritchie JT, Fischer RA, Schulthess U (1995a) Vernalization in wheat. I. A model based on the interchangeability of plant age and vernalization duration. Field Crops Res 41:91-100

Wang SY, Ward RW, Ritchie JT, Fischer RA, Schulthess U (1995b) Vernalization in wheat. II. Genetic variability for the interchangeability of plant age and vernalization duration. Field Crops Res 44:67-72

Weir AH, Bragg PL, Porter JR, Rayner JH (1984) A winter wheat crop simulation model without water or nutrient limitations. J Agric Sci 102:371-382

Xu M (1996) Wheat grain quality as related to climate: evaluation and model development. PhD dissertation, University of Nebraska-Lincoln

Yan WK, Hunt LA (1999a) An equation for modelling the temperature response of plants using only the cardinal temperatures. Ann Bot 84:607-614

Yan WK, Hunt LA (1999b) Reanalysis of vernalization data of wheat and carrot. Ann Bot 84:615-619

Yan WK, Wallace DH (1998) Simulation and prediction of plant phenology for five crops based on photoperiod-temperature interactions. Ann Bot 81:705-716

Yin X, Kropff MJ, Nakagawa H, Horie T, Goudriaan J (1997) A model for photothermal responses of flowering in rice. II. Model evaluation. Field Crops Res 51:201-211

Zadoks JC, Chang TT, Konzak CF (1974) A decimal code for the growth of cereals. Weed Res 14:415-421

Submitted: August 13, 2002; Accepted: November 14, 2003 Proofs received from author(s): January 15, 2004 